Original Research Paper

\title{
Evaluation of Biogas Plants by the Application of an Internal Rate of Return and Debt Service Coverage Approach
}

\author{
Giuseppe Bonazzi and Mattia Iotti \\ Department of Civil Engineering, Environment, Territory and Architecture (DICATeA), University of Parma, Parma, Italy
}

\author{
Article history \\ Received: 23-02-2015 \\ Revised: 01-04-2015 \\ Accepted: 01-04-2015 \\ Corresponding Author: \\ Mattia Iotti \\ Department of Civil Engineering, \\ Environment, Territory and \\ Architecture (DICATeA), \\ University of Parma, Parma, Italy \\ Email: mattia.iotti@unipr.it
}

\begin{abstract}
Energy production using renewable energy has an effect on environmental sustainability and on public expenditure. In fact, this industry is heavily assisted by public support from the European Union and the Italian State. Developing and applying a method to evaluate the return on investment for companies operating in the field of renewable energy allows them to quantify their efficient use of public resources. In this research we develop an assessment method that combines the rate of return on equity capital (IRRE) and financial viability (DSCR), in which IRRE $>\mathrm{Ke}$ and sub DSCR $>1$ for any given period of the investment. This method enables us to quantify both the equity capital return and financial sustainability. The method is applied to a case study of a company's production of biogas from livestock effluents located in the province of Reggio Emilia, Italy. The analysis shows that biogas investment guarantees financial sustainability, even in the case of financial liabilities, in the case examined. It also shows that IRRE is higher than average, with a return on equity assured both by market average (MRP) and government bonds in the long term. The research could be further developed by quantifying the social welfare generated by public spending and private investment as equity capital, both in terms of its activation of the economy and in terms of assessing the environmental effects that qualify as externalities.
\end{abstract}

Keywords: Biogas, Biomass, Positive Externalities, Internal Rate of Return, Net Present Value, Debt Service Coverage Ratio

\section{Introduction}

The use of renewable energy particularly affects agriculture and land use (Cantrell et al., 2008; Pretty, 2008). In fact, agriculture has played a central role in the economy and in the life of man throughout the course of history, as a primary source for meeting our need for food even considering environmental impact (Tilman et al., 2001; Foley et al., 2005; Tilman et al., 2011). Since the industrial revolution and, more recently, with the development of increasingly rapid tertiary activities, agriculture has reduced its rate of incidence in the formation of the national income (Laitner, 2000; Foellmi and Zweimüller, 2008; Chai and Moneta, 2012). At the same time, those employed in agriculture have noticed a sharp contraction, due to technical progress and the specialization of labor (Alvarez-Cuadrado and
Poschke, 2011). This has reduced the need for labor in the primary sector. Today agriculture retains a central role in the socio-economic system, not only in the production of income, but also because of the indirect effect that it has on the environment, landscape and on people's health, as several researches have shown for the Mediterranean Basin (Di Trapani et al., 2014; Sgroi et al., 2015a). This effect is also expressed through the production of public goods, i.e., nonrivalrous and non-excludable goods. Non-rivality is a type of good that can be consumed jointly by several individuals without preventing the possibility of consumption by others. Non-excludability is the inability, or unwillingness, to exclude some potential consumers from the use of a good, for example through price mechanisms. Conversely we have private goods, which are rivalrous and excludable. Mixed goods have 
characteristics that are partly those of public goods and partly those of private goods. Environmental good is a public good, or it is a mixed good, because it produces a share of goods and services characterized as having absolute non-rivality and non-excludability in consumption, while another portion of it may be subject to the system of market prices which represent private production. In this context, for example, energy production through renewable energy is a mixed good, as it generates services which pass through the market, such as energy that is sold. However it also produces environmental services that do not pass through the market, for example the reduction of pollutant emissions. The emissions of a series of goods and services are without price. They are defined as externalities, are freely accessible and do not pass through market mechanisms; externalities are in fact classified as secondary products, additional to the main product, which are beyond the system of market prices. To limit and discourage the issuance of negative externalities and to stimulate the production of positive externalities, the economic literature and legislative interventions have proposed a series of measures aimed at controlling emissions from economic operators that threaten the environment (Barbier, 1987; Kleijn and Sutherland, 2003). The evalutaion is particularly important in situations where the State intervenes with public spending. Specific to our research, public incentives provided in various forms have often aided investments in renewable energy. In fact, the production of energy from renewable sources is generally judged as a positive externality, capable of generating advantages for the community above the cost of public resources used. This condition is essential to ensure that the use of public resources is efficient. In fact, only if the use of public resources generates positive externalities greater than the resources used do we have an efficient use of public spending particularly about food production. The public operator must in fact maximize the efficient use of public resources. The objective of this research is to develop a methodology to evaluate investments in biomass plants, applying this methodology to a case study in an area of the northern Apennines, in the Emilia-Romagna region of Italy. The methodology begins with an estimation of the financial evaluation of these projects, as several researchs have shown (Nemecek et al., 2008) Biomass plants have a close relationship with land and agricultural production, in particular, as in the case analyzed in the research, where they operate jointly with farm production. Our assessment takes great interest in the use of public resources, because of incentive tariffs for the sale of energy and also for the initial investment. This determines the usefulness of analyzing the project with a technical evaluation of the proposed investment.
The analysis is particularly relevant when considering the environmental role of renewable energy sources such as biomass, particularly in terms of the sustainable development of hilly and mountainous rural areas (Sharif Hossain et al., 2008; Sukiran et al., 2009; Shabeeb et al., 2010; Strano et al., 2014; Timmons, 2014; Tudisca et al., 2014; Sgroi et al., 2015a; 2015b). This could be particularly true for renewable energy firms, which are often capital intensive and frequently use financial debt to cover fixed asset investments (Molinos-Senante et al., 2010; Broberg Viklund and Lindkvist, 2015; Coelho et al., 2015). The evaluation indices proposed here may allow a proper assessment, in advance, of the sustainability of the management cycle. Secondly, this analysis could also be useful to limit the inefficient use of public expenditure when evaluating the efficiency of public aid.

\section{Materials and Methods}

\section{Economic and Financial Evaluation Approach}

Through an evaluation of the investment we can quantify, in monetary terms, the convenience of its creation and management. An evaluation of a single (stand alone) investment can be done by considering the asset such as a property, plant, or equipment, or by considering the management of a firm, as a particular type of investment. The investment evaluation uses indices divided into two distinct groups: (1) Economic indices, derived from annual account data and taking an accounting approach; (2) financial indices, derived from financial statement data taking a financial approach. The economic evaluation indices quantify the accounting return of capital by applying a balance ratio, taking into consideration the flow of economic values that are the positive and negative components of income. These ratios consider the time value creation, which is the logical moment of the perfection of operations; this is applied as an accrual value during the accounting practices and the formation of a balance sheet. Applying an economic approach, the main measure of profitability is the Return Of Equity (ROE), which is the ratio between profit and the equity capital. Economic ratios have, by their nature, however some characteristics that limit their application to an evaluation of investments: (1) Ratios are calculated by applying economic and capital values as affected by the provisions of the laws of accounting. On many occasions, the principle of prudence results in the potential underestimation of income, even in the short term and does not allow for any evidence of the latent capital gains of fixed assets, as well as not accounting for the value of intangible assets. In addition, the nonconsideration of assets with positive latent capital gains 
has an influence by decreasing the denominator of economic ratios, such as ROE, with a potential increase in the rate of return estimated as an annual percentage. (2) The ratios are not considered at the time of the manifestation of financial flows, creating situations where an assessment that takes an economic approach, even showing a rate of return considered adequate by equity holders, will suffer from a lack of liquidity and an inability to distribute dividends, even with a positive profit. (3) Flow values in the numerator are put in relation to stock values in the denominator for all economic ratios. The numerator considers the values of flow being formed during the reporting period, from the beginning to the end, as the algebraic sum of the positive and negative components of income, while the denominator considers the values of stocks that have instant quantification. The ratios have a maximum distortion in the case of assessments related to activities that are strongly seasonal, where the quantification of capital stocks at the end of the period is not strongly expressive of the average equity (or debt) used for financing firms. To overcome the limits of economic ratios, a financial approach is frequently applied which quantifies the results of management in terms of cash flow. A financial approach applies indices for evaluating investments with long-term horizons, basing the analysis on the Discounted Cash Flow approach (DCF). These methods consider the occurrence of flows over time, expressing the present value of a future stream of discounted values during a given period of time until a time horizon at the end of the investment. The time horizon is defined as the period within which occur the effects of the investment being valued. It takes into account elements of obsolescence in the investment, as well as legal or contractual constraints and even the personal judgments of the entrepreneur.

\section{Discounted Cash Flow Approach}

We can therefore express (Iotti and Bonazzi, 2012) the present value of a financial flow at a year zero $\left(\Phi_{0}\right)$, detected in a generic year $t\left(\Phi_{t}\right)$ considering a given discount rate $(k)$ Equation 1:

$$
\Phi_{0}=\frac{\Phi_{t}}{(1+k)^{t}}
$$

The investment evaluation, because it is based on discounting at the initial moment of investment, shall consider the initial accumulation of inflows from the investment, at the initial year zero. The accumulation primarily considers the sum of Financial Inflow (FI), for every period $t \in[0, O T]$, with $\mathrm{t}$ as time periods, usually years, since the investment time horizon of $O T$ Equation 2:

$$
F I_{0}=\sum_{t=0}^{O T} \frac{F I_{t}}{(1+k)^{t}}
$$

At the same time we consider the initial accumulation of Financial Outflow (FO), for every period $t \in[0, O T]$ Equation 3:

$$
F O_{0}=\sum_{t=0}^{O T} \frac{F O_{t}}{(1+k)^{t}}
$$

The preferred base of financial flow analysis is cash flow statement (Almeida et al., 2004; Farshadfar and Monem, 2013). To apply discounting methods it is necessary to quantify the discount rate, which can be defined as the user's opportunity cost of capital. In fact, the investment involves absorption of capital that must be financed with equity or debt and this requires a return on capital in favor of the subject that provides it. We can use a subjective evaluation approach for the opportunity cost of the capital, estimating exogenously on a case-by-case basis the minimum level of remuneration acceptable for the entrepreneur, given a quantified risk, to invest and potentially lose, equity capital. This approach is modeled on the Willingness To Pay (WTP) used by economic sciences to quantify the environmental value of the public goods for which there is no market price and for which we need to estimate the relative value, through construction, with interviews and questionnaires: A hypothetical market. If we proceed, however, with this objective methodology, we have, among the methods used to quantify the discount rate, the Weighted Average Cost of Capital (WACC). This rate takes into account the cost of all sources of funding, whether it is equity capital $(E)$ or debt $(D)$. The WACC is calculated as the weighted average cost of debt $(K d)$ and equity $(K e)$. We proceed by expressing the $K d$ as the net of a tax shield for the deduction of interest expenses $\left(1-T_{m}\right)$ where $T_{m}$ is the marginal tax rate. The WACC formula is Equation 4:

$$
\mathrm{WACC}=K d\left(1-T_{m}\right) \frac{D}{D+E}+K e \frac{E}{D+E}
$$

The proposed formula used in the literature, however, needs to be adapted, particularly given the specificity of the different tax systems concerning the calculation of tax. In fact, if only a fraction of the cost of the debt is deductible for tax purposes, as is frequently the case, we suggest the expression Equation 5:

$\mathrm{WACC}=\left(K d-K d^{T} T_{m}\right) \frac{D}{D+E}+K e \frac{E}{D+E}$

In Equation $5 K d$ is the cost of debt while $K d^{T}$ is the cost of the debt deductible for tax purposes. 


\section{Net Present Value (NPV) Approach}

An evaluation of investments can be made, as in the case of the evaluation of firms, from an asset side approach or an equity side approach. The main investment evaluation index based on the financial flow, is the Net Present Value (NPV), even decoupled (Espinoza and Rojo, 2015) for renewable energy feasability studies and even in uncertainity situations (Hallmann and Amacher, 2014); NPV expresses the value of the investment as the sum of the discounted cash flows. It quantifies the wealth in monetary units created or destroyed via the investment. NPV simultaneously considers the time of the flows, the investment time horizon and the discount rate. In the case of a simple investment, characterized by a concentration of investment in the initial year $\left(F_{0}\right)$, it is Equation 6:

$$
\mathrm{NPV}_{0}=\sum_{t=1}^{O T} \frac{\left(F I_{t}-F O_{t}\right)}{(1+k)^{t}}-F_{0}
$$

If it is not possible to isolate the investment to an initial period, or the initial investment exceeds a oneyear period, it is better to consider the actualization cash inflow and the outflow separately. We can also consider the terminal value of the investment at a time horizon $\left(T V_{O T}\right)$, expressed as follows Equation 7:

$$
\mathrm{NPV}_{0}=\sum_{t=0}^{O T} \frac{\mathrm{FI}_{t}}{(1+k)^{t}}-\sum_{t=0}^{O T} \frac{\mathrm{FO}_{t}}{(1+k)^{t}} \pm \frac{\mathrm{TV}_{O T}}{(1+k)^{O T}}
$$

The realization of the investment is convenient only if NPV $>0$. When we have $0 \leq \mathrm{NPV}$ the value generated from the investment is insufficient to cover the invested capital, given the time horizon and risk, synthesized at the discount rate.

\section{IRR Approach}

To quantify the value created in terms of a percentage return, to be compared with the return on alternative investments, it is estimated as the Internal Rate of Return (IRR). The IRR is the rate that equalizes the positive and negative streams of cash, having NPV $=0$ as follows Equation 8:

$$
\sum_{t=0}^{O T} \frac{F I_{t}}{(1+I R R)^{t}}=\sum_{t=0}^{O T} \frac{F O_{t}}{(1+I R R)^{t}}=>\mathrm{NPV}_{0}=0
$$

IRR quantifies the return on investment using unlevered cash flows. The IRR must be greater than the opportunity cost of the capital employed in the investment, expressed by the discount rate $(k)$; if and only if IRR $>\mathrm{k}$ and NPV $>0$. We use the Unlevered Free Cash Flow (UFCF), to quantify an asset side value:

$$
\mathrm{NPV}_{0}^{p}=\sum_{t=0}^{O T} \frac{\mathrm{UFCF}_{t}}{\left(1+\mathrm{WACC}_{t}\right)^{t}}=A V_{0}^{D C F}
$$

In Equation $9 N P V_{0}^{p}$ is the project net present value and $A V_{0}^{D C F}$ is the asset value considering a Discounted Cash Flow (DCF) approach. We use WACC as a discount rate, calculating the WACC value every year, with a punctual $\mathrm{WACC}\left(\mathrm{WACC}_{\mathrm{t}}\right)$ that may be different for each period $t$ (given the different composition of funding sources in terms of equity capital and debt) as well as its consequent impact in terms of a change in the level of risk. Moreover, because UFCF is cash flow before any reduction (or accession) of debt, to quantify NPV for equity holders $\left(N P V_{0}^{E}\right)$ or the equity NPV, we can apply the following formula:

$$
\begin{aligned}
& N P V_{0}^{\mathrm{E}}=\sum_{t=0}^{O T} \frac{U F C F_{t}}{\left(1+W A C C_{t}\right)^{t}}-N F P \\
& =A V_{0}^{D C F}-N F P=E V_{0}^{D C F}
\end{aligned}
$$

In Equation $10 E V_{0}^{D C F}$ is an equity side value. Several researchers have expressed doubt about Equation 10, particularly because it considers the $\mathrm{E}$ value as the missing value of the equation and, at the same time, as a component of the WACC value, as part of Ke (De Miguel and Pindado, 2011). The evaluation directly quantifies an equity side value using Free Cash Flow to Equity (FCFE), which is a stream of net financial flows available to be distributed to equity holders as dividends. The discount rate only considers the implicit cost of equity capital $(\mathrm{Ke})$; the FCFE is the cash flow available to equity holders, from which it follows that the related discount rate is $K e$, because of the already explicit consideration of the cost of debt $(K d)$ in the FCFE flow. In fact, if $K d=0 \Rightarrow$ $\mathrm{WACC}=\mathrm{Ke}$; we express it as follows Equation 11:

$N P V_{0}^{E}=\sum_{t=0}^{\mathrm{OT}} \frac{F C F E_{t}}{\left(1+K e_{t}\right)^{t}}=E V_{0}^{D C F}$

This approach emphasizes that value creation requires returns that are higher than the user cost of capital. The method may also include a consideration of the Terminal Value (TV) to be added to the discounted cash flows. We express that as follows Equation 12:

$$
N P V_{0}^{P}=\sum_{t=0}^{O T} \frac{U F C F_{t}}{\left(1+W A C C_{t}\right)^{t}}+\frac{T V_{O T}}{\left(1+W A C C_{t}\right)^{O T}}=A V_{0}^{D C F}
$$

We can also express the equity NPV (equity side approach), considering the UFCF flows with a WACC 
discount rate and a Terminal Value (TV) net of NFP Equation 13:

$$
\begin{aligned}
& N P V_{0}^{E}=\sum_{t=0}^{O T} \frac{U F C F_{t}}{\left(1+W A C C_{t}\right)^{t}}+\frac{T V_{O T}}{\left(1+W A C C_{t}\right)^{O T}}-N F P= \\
& =A V_{0}^{D C F}-N F P=E V_{0}^{D C F}
\end{aligned}
$$

Alternatively, the NPV of the equity capital (equity side approach) can be expressed by discounting FCFE at the rate $K e$ with consideration of the Terminal Value (TV):

$$
N P V_{0}^{\mathrm{E}}=\sum_{t=0}^{O T} \frac{F C F E_{t}}{\left(1+K e_{t}\right)^{t}}+\frac{T V_{O T}}{\left(1+K e_{t}\right)^{O T}}=E V_{0}^{D C F}
$$

In Equation 14 the investment leads advantage only if $N P V_{0}^{E}>0$; given $K e_{t}$ as the discount rate, we express:

$$
K e_{t}=\frac{d_{t}^{\text {min }}}{E V_{t}^{D C F}}
$$

In Equation $15 d_{t}^{\text {min }}$ is, in a given time $\mathrm{t}$, the minimum dividend required by equity holders, with an equity value of $E V_{t}^{D C F}$. Then we have:

$$
N P V_{0}^{E}=\sum_{t=0}^{O T} \frac{F C F E_{t}}{\left(1+I R R E_{t}\right)^{t}}+\frac{T V_{O T}}{\left(1+I R R E_{t}\right)^{O T}}=0
$$

In Equation 16 the IRRE is the internal rate of equity return that expresses the return on equity flow. On the subject of this assessment, calculations should be carried out with several precautions. Firstly, it is not possible to graduate projects using the criteria of maximum NPV. Indeed, NPV does not take into account the use of capital. Again, to calculate NPV we have to estimate a $K e$ value estimate for every period $t$, considering that $K e$ is the only way to express the risk of the project and on its own assumes the whole risk. IRR, even if characterized by several limitations, is thus one of the most applied and well known approach in investment evaluation. Firstly, in fact, IRR as a criterion for choosing between alternative investments (maximum IRR), suffers from a lack of consideration of the opportunity cost of capital in the calculation and risk of multiple solutions (Ben-Horin and Kroll, 2012; Magni, 2013; Ng and Beruvides, 2015) and does not consider financial constraints (Bagella et al., 2001; Caggese, 2007). We suggest making a choice between alternative investments by basing judgments on the largest positive difference between the IRRE and the discount rate $(\mathrm{Ke})$ quantified for each investment, as follows Equation 17:

$\max (I R R E-K e)$ sub DSCR $>1 \forall$ period $t$ where, DSCR is debt service coverage ratio, calculate the ratio between UFCF and the Debt Service (DS) in any given period $t$ as follows Equation 18:

$$
D S C R_{t}=\frac{U F C F_{t}}{D S_{t}}
$$

The maximum condition of (17) considers that $K e>0$ $\forall$ period $t$, if DSCR $>1$ in any period $\mathrm{t}$. We have that ADSCR $\geq$ UFCF-DS in any given period $t ; K e<0$ only when we (think) that a future time could be preferable than the actual time given the expected risk. We can then consider the quantified IRRE in our analysis of the project with a DSCR for a given period $t$. Thus we can estimate $K e$ in the long run as the return on a treasury bond, being conscious that the return on a treasury bond is at a risk free rate (given the country risk). However, considering this, it is not possible even by increasing the opacity of the model, to properly estimate $K e$ for any given period $t$, even considering the circularity problem (Mejía-Peláez and Vélez-Pareja, 2011).

\section{Results}

The methods used to encourage the production of electricity from renewable sources (excluding photovoltaic systems) were established in Italy by the Decree of the Ministry (DM) on July 6, 2012. These are eligible for incentives to build power plants not less to 1 $\mathrm{kW}$. The incentives apply to new installations that will commence operation on 1 January 2013, fully rebuilt and reactivated, subject to intervention enhancement or restoration. The incentives are recognized on production of net electricity supplied to the grid by the plant. Any electricity that is self-consumed is not part of the incentive scheme. The DM has determined that the cumulative cost indicative of all types of incentives paid to renewable energy plants, other than photovoltaic plants, cannot exceed a total value of 5.8 billion euros per year. The new incentive system also introduced annual capacity eligibility quotas for each year from 2013 to 2015 , divided by type of source and plant and broken down by means of access to the incentives provided by the DM on July 6,2012 . The rates will be reduced by $2 \%$ per year from 2014 , subject to the exceptions provided for in the event of a failure to achieve $80 \%$ of the power of the annual quota provided for logs and for auctions. The value of the incentive fee is payable at the rate applicable on the date of entry into the operation of the plant. The all-inclusive tariff or incentive, calculated from the value of the public tariff basis, will be paid by the GSE from the date of entry into commercial operation. The efficient use of public resources is important in the context of sustainable development and the science of finance, in particular in a situation of global economic crisis where there is a 
reduction in public resources available for use. Sustainable economic development could be reached in a world in which sustainable energy sources are available as an alternative to traditional fossil fuels, which then reduce the impact on the environment as established by Kyoto Protocol. In recent years, renewable energy sources have had an increasing impact on the European Union's (EU) electricity production after Directive 2001/77/EC was issued for the development of renewable energy application in Europe. The energy produced by renewable sources in 2011 was $20.3 \%$ of total EU primary production, while in 2000 it was $10.3 \%$. European policy aid for renewable sources continued with Directive 2009/28/EC: This set a target that $20 \%$ of the EU's consumed energy mix should come from renewable sources by 2020 . The EU defines biomass as the "biodegradable fraction of products, waste and residues of biological origin from agriculture (including vegetal and animal substances), forestry and related industries including fisheries and aquaculture, as well as the biodegradable fraction of industrial and municipal waste." Biomass can be used in power plants that generate electricity or heat and in 2012 solid biomass (wood, wood waste, pellets and other green or animal waste) energy production accounted for 82.3 MTOE. The main European countries for primary energy production are: Germany (11.8 MTOE), France (10.5 MTOE), Sweden (9.4 MTOE), Finland (7.9 MTOE) and Poland (6.9 MTOE). Italy has a production of 4.1 MTOE and a consumption of 5.3 MTOE and is currently the eighth producer in the EU (Sgroi et al., 2015b). The valuation of the use of biomass enables such improved environmental and socio-economic effects as crop diversification, the restoration of abandoned land, maintenance of forests and the creation of jobs (McKendry 2002a). Furthermore, the use of biomass combats global warming because the production budget of greenhouse gases, typically $\mathrm{CO}_{2}$, can be considered almost neutral (Roman and Turnbull, 1997). The choice of technology and the supply planning of biomass are essential to ensure sustainable energy production in the long term and as well as good conversion efficiencies (Rosch and Kaltschmitt 1999; McKendry 2002b). However the production of energy from biomass can also have a negative impact; in particular, we should pay attention to air pollution. There are three types of power plants (a) solid biomass (wood, wood chips, straw, etc.), often operating with traditional systems such as a combustion furnace for solid biomass and a boiler that supplies a steam turbine coupled to a generator; (b) liquid biomass (for various oils such as palm, sunflower, soybean) consisting of engines coupled to generators (sets); (c) biogas obtained from anaerobic digestion (using various substrates such as manure, organic residues, corn or other). Biomass power stations enable combustion at temperatures that typically exceed $800^{\circ} \mathrm{C}$, transforming the raw material of biomass (solid or liquid) into energy in the form of heat. The energy powers a boiler that can provide heating, i.e., the exploitation of thermal energy to heat the surrounding area by increasing the energy efficiency of the system (which represents about 70$75 \%$ of the production), or producing steam to drive a turbine that produces electrical energy (which represents $25-30 \%$ of the potential energy of the system). The biogas plant works through a process of fermentation, digestion and gasification: Transforming the matter through "anaerobic digestion." In the absence of air, bacteria feed on organic matter, producing methane gas and digestate. The digestate is waste (EWC code: 190600-03-04-05-06). The gas collected from the fermentation tanks is then introduced to the central gas engines using electric power of usually less than $1 \mathrm{MW}$ and through combustion electricity and heat are produced. Bio liquids can access incentive mechanisms as long as they comply with sustainability criteria established at European level (Directive 2009/28/EC and Directive 2009/30/EC, implemented in Italy, respectively, with Legislative Decree no. 28/2011 and D. Decree no. 55/2011). Sustainability criteria are used to distinguish those bio liquids that demonstrate a high environmental value, such as products that reduce global emissions of carbon dioxide and (with respect to the land) limit their impact on agricultural products used for food production. Bio liquid productions that hope to benefit from financial support after 2012 must meet certain sustainability criteria. In summary, the sustainability criteria are: (a) Reducing greenhouse gas emissions: The entire chain of production and use of bio liquids (the so-called "life cycle", from the cultivation of raw materials to the final use of the bio liquid) must ensure savings of greenhouse gas emissions, compared to the use of corresponding fossil fuels. This reduction must be equal to at least $35 \%$ (from 2013 in the case of bio liquids produced by installations that were in operation on 23 January 2008). This reduction must then be equal to $50 \%$ by 2017 and $60 \%$ by 2018 . (b) Raw materials that are used to produce bio liquids must not come from high biodiversity land or from land with a high carbon stock. The problem of the localization (Voivontas et al., 2001) of the plants and the definition of basins of contribution is fixed with respect to three goals, as many as the main aspects related to the use of renewable sources: (1) The energy yield (energy target); (2) the reduction of greenhouse gas emissions (target emission); (3) the net monetary return (economic objective). The case under analysis has a significant territorial importance. It is in fact a system operating on biogas, located in hilly area of northern Italy, at an altitude of about 650 meters above sea level. The investment is intended as a standalone venture, in the form of non-limited company, connected to a bovine livestock farm. The installed electricity production was 
$100 \mathrm{kWe}$. The company produces milk for processing into Parmigiano-Reggiano DOP cheese in the province of Reggio Emilia, in the Emilia-Romagna region. Data set was considered in other researches about the theme of interest coverage ratios (Bonazzi and Iotti, 2014; Iotti and Bonazzi, 2015). The company has a total area of 150 hectares, of which 52 are owned and 98 rented. The farm includes two stable free stalls for animals. Milk production is given to a dairy cooperative for processing into cheese. The company owns about 450 cows, as well as a breeding fattening pig weighing between 60 and 160 $\mathrm{kg}$. The firm is legally considered an agricultural firm; in fact Article 1 of the Decree of May 18, n. 228, "Orientation and modernization of the agricultural sector," redefines Article 2135 of the Civil Code, which defines the use of renewable energy as an agricultural activity. The qualification of renewable energy firms as agricultural farms is particularly interesting; in fact, under the terms of Italian bankruptcy law, agricultural firms are not subject to bankruptcy. Again, firms operating as a sole proprietorship of a non-limited company are not allowed to file annual accounts to the registrar of companys' databases as public data. In this way, as in the case study here considered, it was necessary to receive data confidentially from the firm's management and then process it anonymously. In the case study the initial assessment of the biogas plant has been made by considering the total use of all the cattle and pig sewage products. All electricity produced by the company is sold to the company manager Gestore Servizi Energetici Spa (GSE), a state-owned company supporting renewable energy sources in Italy and paid within the parameters of the law at $0.30 € / \mathrm{kWh}$ for 15 years. The amount used was about 12,000 tons of pig slurry, 5,000 tons of cattle slurry and 1,000 tons of cattle manure per year. The total investment was $€ 721,322$ for the construction of the structure property, the purchase of equipment, the CHP and any resulting technical costs. Its useful life was estimated as a total of 10 years. Considering that the plant was built in 2008 and began operation in early 2009 , with data available until the end of 2014, six years of data has been evaluated. An evaluation was performed until 2014 using the historical data and these data were supplemented with forecast standard data for the period of an additional four years until the time horizon of 10 years. It appears plausible that the useful life of the system can be even greater but given that the costs of maintenance increase during its useful life, a time horizon greater than 10 years is not considered. The financing of the property, plant and equipment works as a Fixed Asset investment (FA), is ensured by bank loan with a medium and long-term mortgage, with an initial debt of $€ 400,000$ and 120 months of mortgage payments at a fixed interest rate of $5.25 \%$. The equity capital is $€ 321,322$. We can consider the value of electricity sales as about $€ 220,000$ per year, as detailed in Table 1 . The company has no other income. The yearly running costs that involve money are around $€ 65,000$ (Table 1). To analyze firm's performance is considered its feasability study, as frequently done in several researches (Khademi et al., 2009; Khambalkar et al., 2013; Lanfranchi et al., 2014; Niu et al., 2014; Hsu et al., 2014; Iotti and Bonazzi, 2014a; 2014b) even about life cycle cost and life cycle assesment approaches (Wiloso et al., 2014; Winden et al., 2014). FCFE was positive in any period from 2009 to 2014 and DSCR $>1$ in the same times, thus complying with the financial constraints vinculum of Equation 17; again, it is worth noting that IRRE is $25.37 \%$.

In Table 2 we proposed an estimated 10 years' time horizon investment for the biogas plant. This estimate was developed as a standalone approach without inflation for the forecast period from 2015 to 2018. The forecast considers an average FI of $€ 230,000$ (average period 2008/2013) and an FO of $€ 65,000$ (average period 2008/2013). The data are not determined by extraordinary events, so we could consider these as normalized. It is verified that $\mathrm{DSCR}>1 \forall t$, thus complying with the financial constraints vinculum of Equation 17. Again, it is important to note that IRRE is $32.04 \%$ with an increased value in respect to the 2008/ 2014 time horizon. In the research plan, even if we carry out research by applying our analysis to a single case and certainly although there are limits to the statistical significance of the analysis made, a high level of return emerges, as shown by IRRE, both for historical data and for the whole time horizon data, even when considering part-estimated values. This value is confirmed even in the absence of a quantification of the terminal value.

Table 1. Cash Flow analysis 2008/2013 (Values per year in 0.000/€) historical values

\begin{tabular}{|c|c|c|c|c|c|c|c|}
\hline Value & 2008 & 2009 & 2010 & 2011 & 2012 & 2013 & 2014 \\
\hline Equity capital & $-321,322$ & & & & & & \\
\hline FI & & 225,000 & 223,000 & 231,000 & 219,000 & 240,000 & 236,000 \\
\hline FO & & $-65,000$ & $-69,000$ & $-63,000$ & $-61,000$ & $-60,000$ & $-66,000$ \\
\hline UFCF & & 160,000 & 154,000 & 168,000 & 158,000 & 180,000 & 170,000 \\
\hline DS & & $-56,000$ & $-52,000$ & $-52,000$ & $-52,000$ & $-52,000$ & $-52,000$ \\
\hline FCFE & $-321,322$ & 104,000 & 102,000 & 116,000 & 106,000 & 128,000 & 118,000 \\
\hline DSCR & & 2.86 & 2.96 & 3.23 & 3.04 & 3.46 & 3.27 \\
\hline IRRE & $25.37 \%$ & & & & & & \\
\hline
\end{tabular}

Source: Our processing of directly collected data 
Table 2. Cash Flow analysis 2008/2018 (Values per year in 0.000/€) historical and estimated values

\begin{tabular}{llllllllllll}
\hline Value & 2008 & 2009 & 2010 & 2011 & 2012 & 2013 & 2014 & 2015 & 2016 & 2017 & 2018 \\
\hline Equity capital & $-321,322$ & & & & & & & & & \\
FI & & 225,000 & 223,000 & 231,000 & 219,000 & 240,000 & 236,000 & 230,000 & 230,000 & 230,000 & 230,000 \\
FO & & $-65,000$ & $-69,000$ & $-63,000$ & $-61,000$ & $-60,000$ & $-66,000$ & $-65,000$ & $-65,000$ & $-65,000$ & $-65,000$ \\
UFCF & & 160,000 & 154,000 & 168,000 & 158,000 & 180,000 & 170,000 & 165,000 & 165,000 & 165,000 & 165,000 \\
DS & & $-56,000$ & $-52,000$ & $-52,000$ & $-52,000$ & $-52,000$ & $-52,000$ & $-52,000$ & $-52,000$ & $-52,000$ & $-52,000$ \\
FCFE & $-321,322$ & 104,000 & 102,000 & 116,000 & 106,000 & 128,000 & 118,000 & 113,000 & 113,000 & 113,000 & 113,000 \\
DSCR & & 2.86 & 2.96 & 3.23 & 3.04 & 3.46 & 3.27 & 3.17 & 3.17 & 3.17 & 3.17 \\
IRRE & $32.04 \%$ & & & & & & & & &
\end{tabular}

Source: Our processing of directly collected data

\section{Discussion}

This analysis shows that the case analyzed has a very high efficiency of equity capital invested (IRRE $25.37 \%$ and $32.04 \%$ respectively at a 6 - and 10-year time horizon). This yield is higher by more than 15 percentage points than the Market Risk Premium (MRP) on the stock market average detected and analyzed by the Bank of Italy in 2009 and is higher by more than 20 percentage points compared to the emissions of longterm treasury bonds from the Italian State in 2009 (BTP). The return is high when contrasted with a traditional view of farming that is frequently characterized by a low capital turnover, a low return on capital, the preservation of corporate value and very long payback period. In our case, the investment payback period is about 3 years for the equity, although with a rotation of the investment it amounted to only about 0.3 (ratio between sales and investment). In essence, the return on the investment in biogas is much higher than alternative investments. If the analysis conducted here in a single case will be confirmed by future research expanding the sample, an IRRE so high raises an issue of competition between sectors. To express this, we define IRREb as the rate of return in the biogas market and IRREm the average return of the market. We hypothesize that the market has negligible transaction costs and an absence of legal barriers to access, as well as the free circulation of information on the performance of firms in the sector. If IRREb $>>$ IRREm investments in biogas will increase until IRREb = IRREm; However, given that the yield IRREb is due to the public contribution of the State, it is necessary to consider: (a) The maximum amount of contribution payable by the State on a national scale; (b) the value of the benefit to the environment caused by the presence of biogas plants. From the analysis there seems no doubt that the performance IRREb is so superior to the performance IRREm that this yield spread (IRREbIRREm) $0>>$ means that there will be an increase in the number of firms in the biogas sector from actual time $(t)$ till a time $(t+1)$. However, this increase in the number of firms will increase the environmental effects disbursed by biogas $(\mathrm{Eb})$ whose value, if estimated (VEb), increases the direct economic effects (income) for the community as a result of the production of biogas ( $\mathrm{VYb}$ ) must be higher than the public spending incentive biogas $(\mathrm{Gb})$; so if and only if $(\mathrm{VEb}+\mathrm{VYb})>\mathrm{Gb}$ is convenient to promote the production of biogas ensuring, with public incentives, performance as IRREb $>$ IRREm. This analysis, shown here in a simplified form, in a single period $(t)$, remains the same even if conducted in a long period OT, [0, OT]. Moreover, in this case the problem is not resolved by the quantification of a social discount rate, which can be approximated, with the performance of treasury bonds in the long term (the corresponding period). The constraint of social convenience can be expressed as $(\mathrm{VEb}+\mathrm{VYb})>\mathrm{Gb} \leftrightarrow$ $\mathrm{NEWb}>0$ where $\mathrm{NEWb}$ is net economic welfare, given by the policy of public aid in favor of investment biogas paid with public expenditure.

\section{Conclusion}

The analysis highlights that firms in the renewable energy sector perform an environmental service socially relevant in terms of emissions of positive externalities, so that the policies of public aid from the European Union and the Italian State have made a significant impact on the performance of the equity capital, as measured by performance index IRRE. This return is far higher than the average return on the market, so it becomes useful to extend the analysis beyond the case study considered. In fact our analysis expresses that in the case study here considered IRREb $>>$ IRRm having then to verify if $(\mathrm{VEb}+\mathrm{VYb})>\mathrm{Gb}$. This verification has an even greater utility, having by definition, $\mathrm{VEb}>0$, as positive externalities, while if it were $\mathrm{VEb}<0$, as negative externalities, it would not be useful that $\mathrm{Gb}>0$, as this would be limiting to the effects on the environment. Future research will then focus on: (1) Increasing the number of cases considered to verify IRRb; (2) quantify the value of $\mathrm{VEb}+\mathrm{VYb}$, particularly verifying that $\mathrm{VEb}>0$; (3) testing whether it is assured that $(\mathrm{VEb}+\mathrm{VYb})>\mathrm{Gb} \leftrightarrow \mathrm{NEWb}>0$.

\section{Acknowledgement}

The researchers would thank analisiaziendale.it for IT assistance, particularly in the database management. 


\section{Author's Contributions}

The article is a result of the full collaboration of all the authors. However Giuseppe Bonazzi wrote paragraphs Introduction, Discounted cash flow approach, Results, Conclusion. Mattia Iotti wrote paragraphs Economic and financial evaluation approach, NPV approach, IRR approach, Discussion.

\section{Ethics}

The authors have no conflicts of interest in the development and publication of current research.

\section{References}

Almeida, H., M. Campello and M.S. Weisbach, 2004. The cash flow sensitivity of cash. J. Finance, 59: 17771804. DOI: 10.1111/j.1540-6261.2004.00679.x

Alvarez-Cuadrado, F. and M. Poschke, 2011. Structural change out of agriculture: Labor push versus labor pull. Economic Syst., 35: 208-229. DOI: $10.1257 / \mathrm{mac} .3 .3 .127$

Bagella, M., L. Becchetti and A. Caggese, 2001. Financial constraints on investments: A three-pillar approach. Res. Econom., 55: 219-254.

Ben-Horin, M. and Y. Kroll, 2012. The limited relevance of the multiple IRRs. Eng. Economist, 57: 101-118. DOI: 10.1080/0013791X.2012.677113

Barbier, E.B., 1987. The concept of sustainable economic development. Environ. Conserv., 14: 101-110. DOI: 10.1017/S0376892900011449

Bonazzi, G. and M. Iotti, 2014. Interest Coverage Ratios (ICRs) and financial sustainability: Application to firms with bovine dairy livestock. Am. J. Agric. Biol. Sci., 9: 482-489. DOI: 10.3844 /ajabssp.2014.482.489

Broberg Viklund, S. and E. Lindkvist, 2015. Biogas production supported by excess heat-a systems analysis within the food industry. Energy Conver. Manage., 91: 249-258.

DOI: 10.1016/j.enconman.2014.12.017

Cantrell, K.B., T. Ducey, K.S. Ro and P.G. Hunt, 2008. Livestock waste-to-bioenergy generation opportunities. Bioresource Technol., 99: 7941-7953. DOI: 10.1016/j.biortech.2008.02.061

Caggese, A., 2007. Testing financing constraints on firm investment using variable capital. J. Finan. Econom., 86: 683-723. DOI: $10.1016 /$ j.jfineco.2006.11.005

Chai, A. and A. Moneta, 2012. Back to Engel? Some evidence for the hierarchy of needs. J. Evolut. Econom., 22: 649-676.

DOI: $10.1007 / \mathrm{s} 00191-012-0283-3$
Coelho, B., A. Oliveira, P. Schwarzbözl and A. Mendes, 2015. Biomass and Central Receiver System (CRS) hybridization: Integration of syngas/biogas on the atmospheric air volumetric CRS heat recovery steam generator duct burner. Renewable Energy, 75: 665-674. DOI: $10.1016 /$ j.renene. 2014.10 .054

De Miguel, A. and J. Pindado, 2001. Determinants of capital structure: New evidence from Spanish panel data. J. Corporate Finance, 7: 77-99. DOI: 10.1016/S0929-1199(00)00020-1

Di Trapani, A.M., R. Squatrito, M. Foderà, R. Testa and S. Tudisca et al., 2014. Payment for environmental services for the sustainable development of the territory. Am. J. Environ. Sci., 10: 480-488. DOI: 10.3844/ajessp.2014.480.488

Espinoza, R.D. and J. Rojo, 2015. Using DNPV for valuing investments in the energy sector: A solar project case study. Renewable Energy, 75: 44-49. DOI: 10.1016/j.renene.2014.09.011

Farshadfar, S. and R. Monem, 2013. Further evidence on the usefulness of direct method cash flow components for forecasting future cash flows. Int. J. Account., 48: 111-133. DOI: $10.1016 /$ j.intacc.2012.12.001

Foellmi, R. and J. Zweimüller, 2008. Structural change, Engel's consumption cycles and Kaldor's facts of economic growth. J. Monetary Econom., 55: 1317-1328. DOI: 10.1016/j.jmoneco.2008.09.001

Foley, J.A., R. DeFries, G.P. Asner, N. Ramankutty and P.K. Snyder, 2005. Global consequences of land use. Science, 309: 570-574. DOI: $10.1126 /$ science. 1111772

Hallmann, F.W. and G.S. Amacher, 2014. Uncertain emerging biomass markets, ecosystem services and optimal land use. Forest Policy Econom., 47: 46-56. DOI: 10.1016/j.forpol.2014.05.009

Hsu, C.W., Y.C. Li, C.Y. Chu, C.M. Liu and S.Y. Wu, 2014. Feasibility evaluation of fermentative biomass-derived gas production from condensed molasses in a continuous two-stage system for commercialization. Int. J. Hydrogen Energy, 39: 19389-19393. DOI: 10.1016/j.ijhydene.2014.07.171

Iotti, M. and G. Bonazzi, 2012. Evaluation of industrial investments: Some hypothesis of methodological improvement. Int. J. Bus. Behav Sci., 2: 1-10.

Iotti, M. and G. Bonazzi, 2014a. The application of Life Cycle Cost (LCC) approach to quality food production: A comparative analysis in the Parma PDO ham sector. Am. J. Applied Sci., 11, 1492-1506. DOI: 10.3844/ajassp.2014.1492.1506

Iotti, M. and G. Bonazzi, 2014b. Life cycle flow analysis: Methodological improvement and application to the Parma PDO ham sector. QualityAccess Success, 15: 98-103. 
Iotti, M. and G. Bonazzi, 2015. Application of ICRs with a Net Financial Position (NFP) repayment approach in the Parma PDO ham sector. J. Food Agric. Environ., 13: 109-114.

Khademi, A., S. Babaei and A. Mataji, 2009. A study on potentiality of carbon storage and $\mathrm{CO}_{2}$ uptake in the biomass and soil of coppice stand. Am. J. Environ. Sci., 5: 346-351. DOI: 10.3844 /ajessp.2009.346.351

Khambalkar, V.P., U.S. Kankal, D.S. Karale and C.N. Gangde, 2013. Biomass energy cost and feasibility of gasifier based biomass power generation system. Int. J. Agric. Biol. Eng., 6: 55-63.

Kleijn, D. and W.J. Sutherland, 2003. How effective are European agri-environment schemes in conserving and promoting biodiversity? J. Applied Ecol., 40: 947-969. DOI: $10.1111 / \mathrm{j} .1365-2664.2003 .00868 . \mathrm{x}$

Laitner, J., 2000. Structural change and economic growth. Rev. Econom. Stud., 67: 545-561. DOI: $10.1111 / 1467-937 X .00143$

Lanfranchi, M., C. Giannetto and A. Puglisi, 2014. A cost-benefits analysis for risk management in a biological farm. Applied Math. Sci., 8: 775-787. DOI: 10.12988/ams.2014.312702

Magni, C.A., 2013. The internal rate of return approach and the airr paradigm: A refutation and a corroboration. Eng. Economist, 58: 73-111. DOI: 10.1080/0013791X.2012.745916

McKendry, P., 2002a. Energy production from biomass (part 1): Overview of biomass. Bioresource Technol., 83: 37-46. DOI: $10.1016 / \mathrm{S} 0960-8524(01) 00118-3$

McKendry, P., 2002b. Energy production from biomass (part 2): Conversion technologies. Bioresource Technol., 83: 47-54. DOI: $10.1016 / \mathrm{S} 0960-8524(01) 00119-5$

Mejía-Peláez, F. and I. Vélez-Pareja, 2011. Solución analítica al problema de la circularidad usando flujos de caja descontados (Analytical solution to the circularity problem in the discounted cash flow valuation framework). Innovar, 21: 55-68.

Molinos-Senante, M., F. Hernández-Sancho and R. SalaGarrido, 2010. Economic feasibility study for wastewater treatment: A cost-benefit analysis. Sci. Total Environ., 408: 4396-4402.

DOI: $10.1016 /$ j.scitotenv.2010.07.014

Nemecek, T., J.S. von Richthofen, G. Dubois, R. Charles and H. Pahl, 2008. Environmental impacts of introducing grain legumes into European crop rotations. Eur. J. Agronomy, 28: 380-393.

DOI: $10.1016 /$ j.eja.2007.11.004
Ng, E.H. and M.G. Beruvides, 2015. Multiple internal rate of return revisited: Frequency of occurrences. Eng. Econom., 60: 75-87. DOI: 10.1080/0013791X.2013.865149

Niu, Y., Y. Liu, H. Tan and S. Hui, 2014. Economic feasibility study of different biomass firing models in China. Energy Proc., 61: 767-771. DOI: 10.1016/j.egypro.2014.11.961

Pretty, J., 2008. Agricultural sustainability: Concepts, principles and evidence. Philosophical Trans. Royal Society B, 363: 447-465.

DOI: $10.1098 /$ rstb.2007.2163

Roman, U. and J. Turnbull, 1997. Integrated biomass energy systems and emissions of carbon dioxide. Biomass Bioenergy, 13: 333-343. DOI: 10.1016/S0961-9534(97)00043-3

Rosch, C. and M. Kaltschmitt, 1999. Energy from biomass-do non-technical barriers prevent an increased use? Biomass Bioenergy, 16: 347-356. 10.1016/S0961-9534(98)00088-9

Sgroi, F., M. Candela, A.M. Di Trapani, M. Foderà and R. Squatrito et al., 2015a. Economic and financial comparison between organic and conventional farming in Sicilian lemon orchards. Sustainability, 7: 947-961. DOI: 10.3390/su7010947

Sgroi, F., A.M. Di Trapani, M. Foderà, R. Testa and S. Tudisca, 2015b. Economic assessment of Eucalyptus (spp.) for biomass production as alternative crop in Southern Italy. Renewable Sustainable Energy Rev., 44: 614-619. DOI: $10.1016 /$ j.rser.2015.01.032

Shabeeb, K.M., K.A. Sukkar, R.A. Azeez, N.J. Salah and M.A. Yousif et al., 2010. A new development in biological process for wastewater treatment to produce renewable fuel. Am. J. Applied Sci., 7: 1400-1405. DOI: 10.3844/ajassp.2010.1400.1405

Sharif Hossain, A.B.M., A. Salleh, A.N. Boyce, P. chowdhury and M. Naqiuddin, 2008. Biodiesel fuel production from algae as renewable energy. Am. J. Biochem. Biotechnol., 4: 250-254. DOI: 10.3844/ajbbsp.2008.250.254

Strano, A., A.I. De Luca, C. Marcianò and G. Gulisano, 2014. The agronomic utilisation of Olive Mill Wastewater (OMW): Technical and economic tradeoffs in olive growing in Calabria (South Italy). Quality-Access Success, 15: 86-91.

Sukiran, M.A., C.M. Chin and N.K.A. Bakar, 2009. Biooils from pyrolysis of oil palm empty fruit bunches. Am. J. Applied Sci., 6: 869-875. DOI: 10.3844/ajassp.2009.869.875

Tilman, D., J. Fargione, B. Wolff, D. Simberloff and D. Swackhamer, 2001. Forecasting agriculturally driven global environmental change. Science, 292: 281-284. DOI: 10.1126/science. 1057544 
Tilman, D., C. Balzer, J. Hill and B.L. Befort, 2011. Global food demand and the sustainable intensification of agriculture. Proc. Nat. Acad. Sci. USA., 108: 20260-20264.

DOI: $10.1073 /$ pnas. 1116437108

Timmons, D., 2014. Using former farmland for biomass crops: Massachusetts landowner motivations and willingness to plant. Agric. Resource Econom. Rev., 43: 419-437.

Tudisca, S., A.M. Di Trapani, F. Sgroi and R. Testa, 2014. Organic farming and economic sustainability: The case of Sicilian durum wheat. Quality-Access Success, 15: 93-96.
Voivontas, D., D. Assimacopulos and E.G. Koukios, 2001. Aessessment of biomass potential for power production: A GIS based method. Biomass Bionergy, 20: 101-112. DOI: 10.1016/S0961-9534(00)00070-2

Winden, M., N. Cruze, T. Haab and B. Bakshi, 2014. Integrating life-cycle assessment and choice analysis for alternative fuel valuation. Ecol. Econom., 102: 83-93. DOI: 10.1016/j.ecolecon.2014.03.008

Wiloso, E.I., C. Bessou and R. Heijungs, 2014. Methodological issues in comparative life cycle assessment: Treatment options for empty fruit bunches in a palm oil system. Int. J. Life Cycle Assess., 20: 204-216. DOI: 10.1007/s11367-014-0815-1 